\title{
Case Report \\ Polyostotic Fibrous Dysplasia with Epiphyseal Involvement in Long Bones: A Case Report
}

\author{
Tomoaki Fukui, ${ }^{1,2}$ Teruya Kawamoto, ${ }^{2}$ Toshiaki Hitora, ${ }^{1}$ \\ Yoshiki Yamagami, ${ }^{1}$ Toshihiro Akisue, ${ }^{2}$ and Tetsuji Yamamoto ${ }^{1}$ \\ ${ }^{1}$ Department of Orthopaedic Surgery, Kagawa University, 1750-1 Ikenobe, Miki-cho, Kida-gun, Kagawa 761-0793, Japan \\ ${ }^{2}$ Department of Orthopaedic Surgery, Kobe University Graduate School of Medicine, 7-5-2 Kusunoki-cho, Chuo-ku, \\ Kobe Hyogo 650-0017, Japan
}

Correspondence should be addressed to Tomoaki Fukui; tomoakifukui@yahoo.co.jp

Received 10 February 2013; Accepted 17 March 2013

Academic Editors: P.-Q. Chen, K. Erler, and D. A. Fisher

Copyright (C) 2013 Tomoaki Fukui et al. This is an open access article distributed under the Creative Commons Attribution License, which permits unrestricted use, distribution, and reproduction in any medium, provided the original work is properly cited.

Fibrous dysplasia (FD) is an uncommon, but well-known benign skeletal disorder. In cases affecting long bones, FD is commonly recognized to locate in the diaphyses or the metaphyses and to spare the epiphyses. In this paper, we present a rare case of polyostotic FD in a 13-year-old girl with unilateral multiple epiphyseal lesions arising in the femur, the tibia, and the fibula with the growth plates.

\section{Introduction}

Fibrous dysplasia (FD) is a sporadic, tumor-like, benign skeletal disorder originally described by Lichtenstein in 1938 [1] and by Lichtenstein and Jaffe in 1942 [2]. FD is often asymptomatic. However, FD often leads to bone pain, deformities, or pathological fractures. FD is classified into two types: monostotic FD affects only a single bone, and polyostotic FD presents the involvement of multiple bones. While small monostotic FD lesions occur more frequently than polyostotic FD, they result in fewer complications. Conversely, polyostotic lesions tend to enlarge and result in severe complications [3, 4]. In cases affecting tubular bones, FD is commonly recognized to occur in the diaphyses or the metaphyses and to spare the epiphyses $[5,6]$. In the present study, we describe a rare case of polyostotic FD with unilateral multiple epiphyseal lesions arising in long bones with the growth plates.

\section{Case Presentation}

A 13-year-old girl was referred to our department with dull pain in the right knee while in motion, which she had noticed approximately one month before her initial visit. There was no pain at rest, swelling, or tenderness in the lower right limb. The range of motion was not limited in the right hip, the right knee, or the right ankle. There was no history of endocrine dysfunction including precocious puberty, and no cutaneous abnormality was found.

Radiographs of the right lower limb revealed multiple radiolucent lesions with sclerotic contours in the diaphyses of the femur the tibia, the patella, the pelvis, and the tarsal bones. Characteristic lesions were also found in the distal epiphysis of the femur, and the proximal and distal epiphyses of the tibia. The growth plates in both the femora and the tibia had not been closed. The lesions in the diaphyses of the right femur and the right tibia were distended causing the surrounding cortex to thin (Figure 1). Technetium bone scintigram showed increased uptake in the diaphyses of the right femur and the right tibia and the right pelvis and around the bilateral knees and ankles (Figure 2). On magnetic resonance imaging (MRI), the epiphyseal lesions of the distal femur and the proximal tibia showed a low signal intensity on T1weighted images and a high signal intensity on fat-suppressed T2-weighted images, and the lesions were markedly enhanced by gadolinium (Figure 3 ).

On the basis of radiological findings, benign bone tumors, such as polyostotic FD or nonossifying fibroma, were 

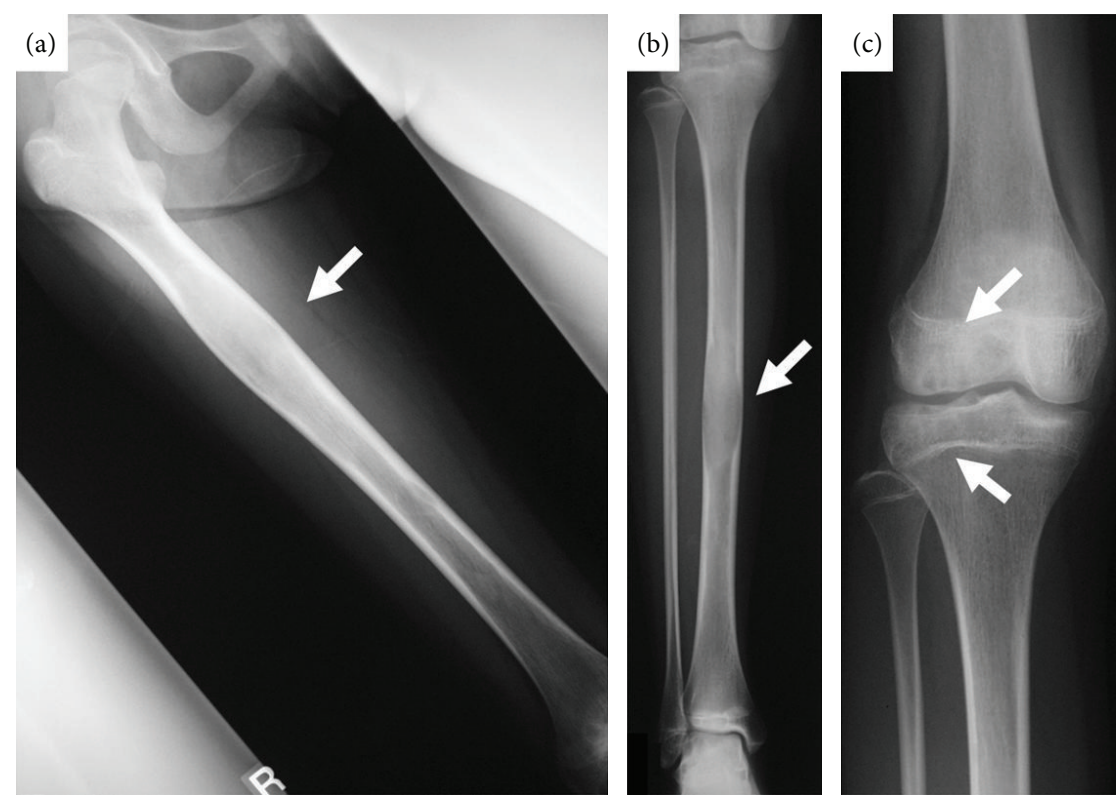

FIGURE 1: Plain radiographs of the right leg. Radiolucent lesions with sclerotic contours in the diaphyses of the right femur (a) and the right tibia (b) and the epiphyses of the right knee (c).

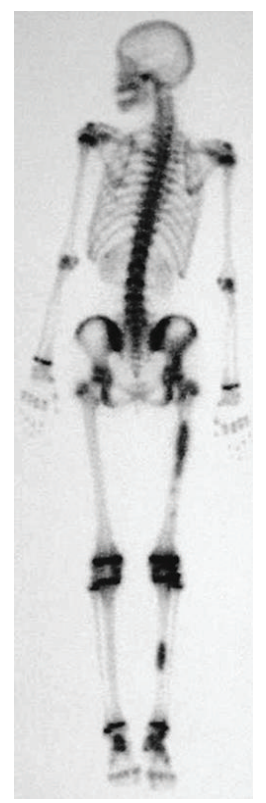

Figure 2: Technetium bone scintigram. Abnormal uptakes are shown in the diaphyses of the right femur and the right tibia and around the bilateral knees and ankles.

suspected. The patient underwent curettage and filling with granules of beta-tricalcium phosphate $(\beta$-TCP) for the lesion in the diaphysis of the right femur, and the histological diagnosis was FD. Two months after the first surgery, surgeries for the lesions in the diaphysis of the right tibia and in the epiphysis of the right femur were performed. Curettage and filling with granules of $\beta$-TCP were performed for the lesion of the tibia, which was diagnosed as FD by postoperative histological examination. As FD does not usually arise in the epiphysis, an open biopsy alone was performed for the distal epiphyseal lesion of the right femur in order to make a definitive diagnosis. The lesion in the epiphysis of the distal femur was histologically composed of haphazard bony trabeculae and fibrous tissue stroma containing benign spindle cells. The trabeculae consisted of immature woven bone, the form of which resembled "alphabet soup." There was lack of osteoblast rimming surrounding the trabeculae (Figure 4). A histological diagnosis of FD was made. Three months after the second surgery, the patient fell and sustained a fracture in the proximal diaphysis of the right femur 

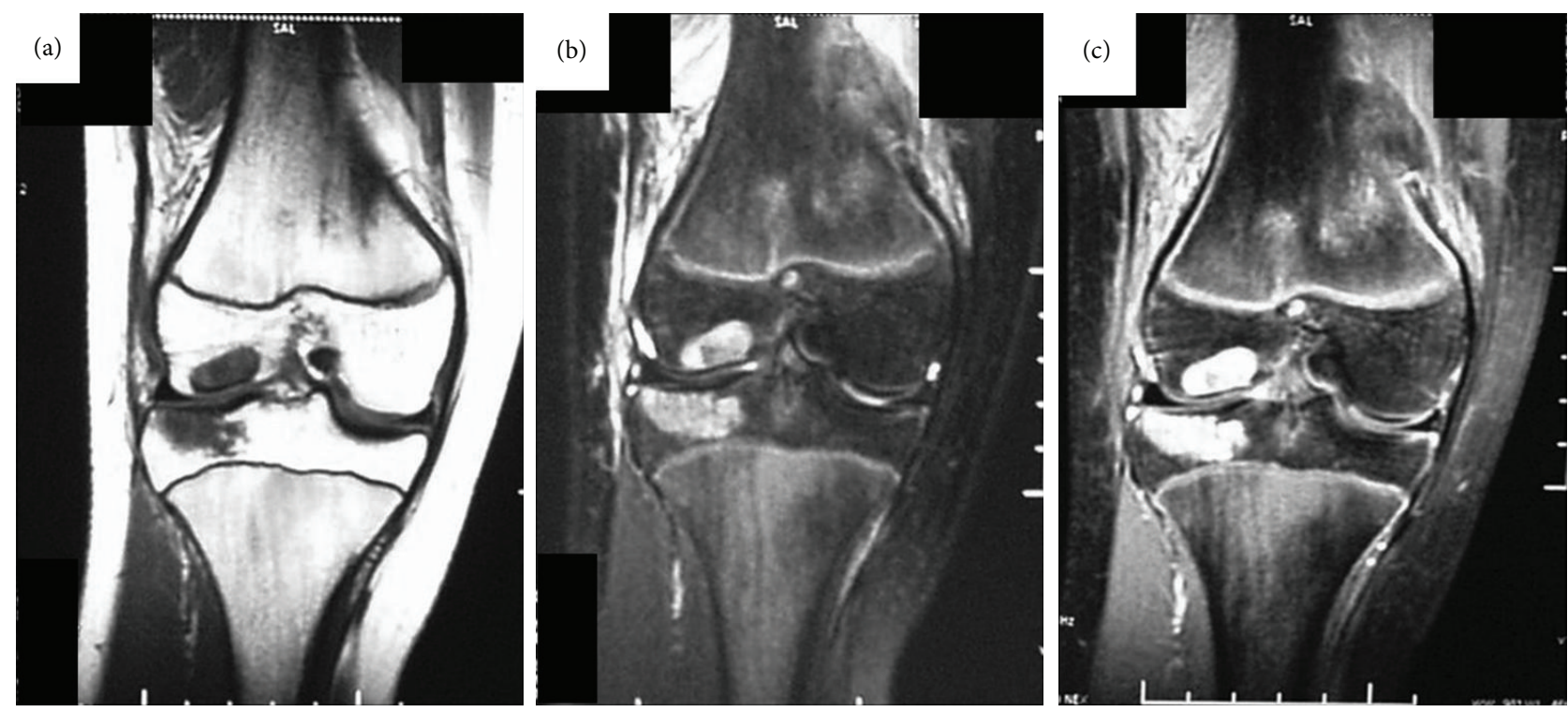

FIGURE 3: Magnetic resonance imaging (MRI) of the lesions in the distal epiphysis of the right femur and the proximal epiphysis of the right tibia. All lesions show a low signal intensity on a T1-weighted image (a) and a high signal intensity on a fat-suppressed T2-weighted image (b). The lesions were strongly enhanced by gadolinium ((c) T1-weighted images enhanced by gadolinium).

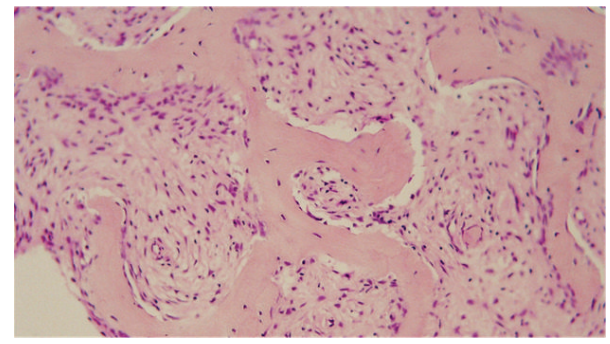

FIGURE 4: Microscopic findings of the excised lesion in the distal epiphysis of the right femur. Spindle cells grow in storiform pattern around haphazard bony trabeculae and fibrous tissue stroma. There is lack of osteoblast rimming surrounding the trabeculae. (hematoxylin and eosin staining; $\times 400$ ).

and underwent osteosynthesis using an intramedullary nail. There was no recurrence in the lesions in the diaphyses of the right femur and the right tibia, and the epiphyseal lesions of the distal femur and the proximal tibia showed no increase in size radiographically at the final follow-up examination (Figure 5).

\section{Discussion}

FD is an uncommon, but well-known benign skeletal disorder, which is considered to be a pathological condition as a result of developmental failure in the remodeling of immature bone to mature lamellar bone and of inappropriate bone realignment in response to a mechanical stress. The disorder of bone maturation leaves a mass of immature isolated trabeculae (woven bone) in dysplastic fibrous tissue [7]. The true incidence of FD is unclear. However, it has been reported that FD represents approximately 5 to $7 \%$ of benign bone

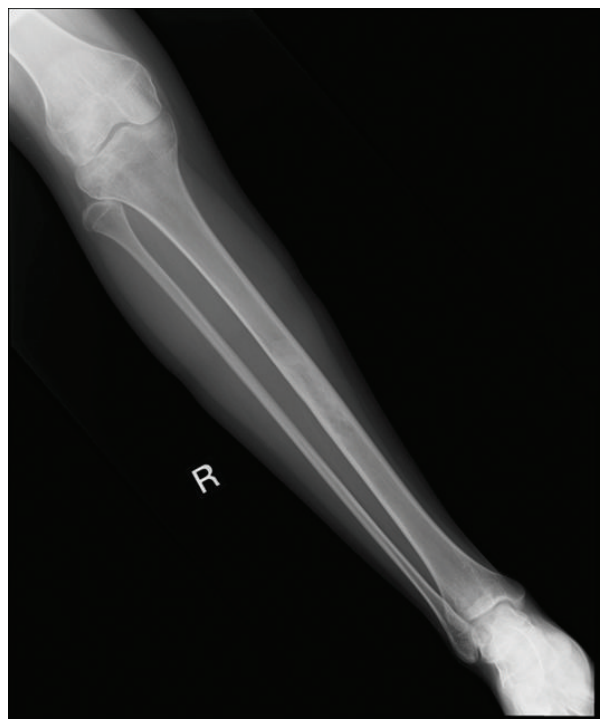

FIGURE 5: Plain radiographs of the right knee five years after the first surgery.

tumors [3]. FD can occur as monostotic or polyostotic lesions. The latter form of FD is rarely accompanied by endocrine dysfunction, including precocious puberty and cafe-aulait spots such as characteristic cutaneous abnormalities, known as McCune-Albright syndrome. According to previous reports, the proportion of monostotic $\mathrm{FD}$, polyostotic $\mathrm{FD}$, and McCune-Albright syndrome is approximately $50 \%-70 \%$, $20 \%-30 \%$ and $3 \%-10 \%$, respectively $[3,4,8-13]$. As a rule, both monostotic and polyostotic lesions affecting long bones such as the tibia, the femur, or the humerus occur in the diaphyses or the metaphyses. Albright first postulated that the 
TABLE 1: Summary of 5 cases of FD with epiphyseal lesions and the current case.

\begin{tabular}{|c|c|c|c|c|c|c|c|c|c|}
\hline Case & Sex & Initial complaint & $\begin{array}{l}\text { Age } \\
\text { of } \\
\text { onset }\end{array}$ & $\begin{array}{l}\text { Age at } \\
\text { followup }\end{array}$ & Pigmentation & $\begin{array}{l}\text { Precocious } \\
\text { sexuality }\end{array}$ & $\begin{array}{l}\text { Location of } \\
\text { epiphyseal } \\
\text { involvement }\end{array}$ & $\begin{array}{l}\text { Monostotic } \\
\text { or } \\
\text { polyostotic }\end{array}$ & Reporter \\
\hline 1 & $\mathrm{M}$ & $\begin{array}{l}\text { Right femoral pain } \\
\text { due to pathological } \\
\text { fracture of femoral } \\
\text { diaphysis }\end{array}$ & 3 & 7 years & None & None & $\begin{array}{l}\text { Bilateral proximal } \\
\text { femurs, right } \\
\text { proximal tibia }\end{array}$ & Polyostotic & Nixon \\
\hline 2 & $\mathrm{~F}$ & $\begin{array}{l}\text { Left hip discomfort } \\
\text { and deformity of the } \\
\text { left lower extremity }\end{array}$ & 12 & Unknown & None & None & $\begin{array}{l}\text { Left proximal femur, } \\
\text { left proximal tibia }\end{array}$ & Polyostotic & Nixon \\
\hline 3 & M & Difficulty in running & 5 & 13 years & Neck, buttock & None & $\begin{array}{l}\text { Left proximal } \\
\text { humerus }\end{array}$ & Polyostotic & Harris \\
\hline 4 & M & Limp & 4 & 30 years & $\begin{array}{c}\text { Forehead, } \\
\text { buttock, finger }\end{array}$ & None & Right distal humerus & Polyostotic & Harris \\
\hline 5 & M & Left knee pain & 13 & 8 months & None & None & Left proximal tibia & Monostotic & Takechi \\
\hline $\begin{array}{l}\text { The current } \\
\text { case }\end{array}$ & $\mathrm{F}$ & Right knee pain & 13 & 3 years & None & None & $\begin{array}{l}\text { Right distal femur, } \\
\text { right proximal tibia, } \\
\text { right distal tibia }\end{array}$ & Polyostotic & \\
\hline
\end{tabular}

FD bone lesions would spare the epiphyses [14], and several subsequent authors have also reported that epiphyses are not usually affected by FD $[5,6,15]$. On the other hand, several authors have reported that lesions in diaphyses or metaphyses can progress with growth and result in the involvement of the epiphyseal area in adults $[5,6,15-17]$. However, cases of FD with epiphyseal involvement before puberty are quite rare; we found only 5 cases in previous reports $[14,16,18,19]$ (Table 1). Epiphyseal involvement in the proximal tibia was shown in 3 of 5 cases, and the current case is the only case that presents epiphyseal lesions in both the distal femur and the distal tibia. Harris et al. reported two cases of polyostotic FD with epiphyseal involvement. However, he did not describe the pathological findings of the involvement [16]. Nixon and Condon also presented two cases of polyostotic FD with epiphyseal lesions and reported that fibroosseous aberration initially occurred in the epiphyseal growth plate and occasionally showed a bidirectional extension into the metaphysis and epiphysis across the growth plate [18]. In the current case, all the long bones with epiphyseal involvements had diaphyseal or epiphyseal lesions, which is compatible with the theory of Nixon and Condon concerning the advancement of FD.

FD lesions are structurally fragile and often present in pathological fractures and in cases involving deformities. FD in the epiphyseal area is likely to induce roughened articular surface. Therefore, it is necessary to observe symptoms and radiographic findings carefully. In the current case, an open biopsy was performed for the distal epiphyseal lesion in the right femur, and the lesions in the proximal and the distal epiphyses of the right tibia were managed by observation only. Although the course was not problematic, we should consider that these lesions may affect articular surface and may require long-term observation.

Although the case presented in the current study is extremely rare, we should take notice of two points in order to prevent oversight: one is to include FD in differential diagnoses when polyostotic tumors or tumor-like lesions occur in epiphyses. The other is to verify whether there is epiphyseal involvement or not when suspecting FD.

\section{Acknowledgment}

The authors presented the current fibrous dysplasia case at the 40th annual musculoskeletal tumor meeting of the Japanese Orthopaedic Association in 2007.

\section{References}

[1] L. Lichtenstein, "Polyostotic fibrous dysplasia," Archives of Surgery, vol. 36, pp. 874-898, 1938.

[2] L. Lichtenstein and H. L. Jaffe, "Fibrous dysplasia of bone. A condition affecting one, several or many bones, the graver cases of which may present abnormal pigmentation of skin, premature sexual development, hyperthyroidism or still other extraskeletal abnormalities," Archives of Pathology, vol. 33, pp. 777-816, 1942.

[3] M. R. DiCaprio and W. F. Enneking, "Fibrous dysplasia: pathophysiology, evaluation, and treatment," Journal of Bone and Joint Surgery A, vol. 87, no. 8, pp. 1848-1864, 2005.

[4] A. Henry, "Monostotic fibrous dysplasia," Journal of Bone and Joint Surgery B, vol. 51, no. 2, pp. 300-306, 1969.

[5] H. A. Fairbank, "Fibrocystic disease of bone," Journal of Bone and Joint Surgery B, vol. 32, no. 3, pp. 403-423, 1950.

[6] C. K. Warrick, "Polyostotic fibrous dysplasia, Albright's syndrome, a review of the literature and report of four male cases, two of which were associated with precocious puberty," Journal of Bone and Joint Surgery B, vol. 31, no. 2, pp. 175-183, 1949.

[7] W. F. Enneking, R. Rathe, and G. Cornwall, "Clinical musculoskeletal pathology," Office of Medical Informatics at the University of Florida, 1998, http://www.medinfo.ufl.edu/cme/ mspath/.

[8] M. D’Armiento, G. Reda, A. Camagna, and L. Tardella, "McCune-Albright syndrome: evidence for autonomous multiendocrine hyperfunction," Journal of Pediatrics, vol. 102, no. 4, pp. 584-586, 1983. 
[9] J. B. Gregg and A. Reed, "Monostotic fibrous dysplasia in the temporal bone: a late prehistoric occurrence," American Journal of Physical Anthropology, vol. 52, no. 4, pp. 587-593, 1980.

[10] K. S. Pelzmann, D. Z. Nagel, and W. R. Salyer, "Case report 114," Skeletal Radiology, vol. 5, no. 2, pp. 116-118, 1980.

[11] H. M. Stauffer, R. K. Arbuckle, and E. E. Aegerter, "Polyostotic fibrous dysplasia with cutaneous pigmentation and congenital arteriovenous aneurysms," The Journal of Bone \& Joint Surgery, vol. 23, pp. 323-334, 1941.

[12] A. G. Huvos, Bone Tumors: Diagnosis, Treatment, and Prognosis, W. B. Saunders, Philadelphia, Pa, USA, 2nd edition, 1990.

[13] E. Ippolito, E. W. Bray, A. Corsi et al., "Natural history and treatment of fibrous dysplasia of bone: a multicenter clinicopathologic study promoted by the European Pediatric Orthopaedic Society," Journal of Pediatric Orthopaedics Part B, vol. 12, no. 3 , pp. 155-177, 2003.

[14] F. Albright, A. M. Butler, A. O. Hampton, and P. Smith, "Syndrome characterized by osteitis fibrosa disseminate, areas of pigmentation and endocrine dysfunction, with precocious puberty in females: report of 5 cases," The New England Journal of Medicine, vol. 216, pp. 727-746, 1937.

[15] M. L. Daves and J. H. Yardley, "Fibrous dysplasia of bone," The American Journal of the Medical Sciences, vol. 234, no. 5, pp. 590-606, 1957.

[16] W. H. Harris, H. R. Dudley Jr., and R. J. Barry, “The natural history of fibrous dysplasia. An orthopaedic, pathological, and roentgenographic study," The Journal of Bone \& Joint Surgery A, vol. 44, pp. 207-233, 1962.

[17] P. D. Latham, N. A. Athanasou, and C. G. Woods, "Fibrous dysplasia with locally aggressive malignant change," Archives of Orthopaedic and Trauma Surgery, vol. 111, no. 3, pp. 183-186, 1992.

[18] G. W. Nixon and V. R. Condon, "Epiphyseal involvement in polyostotic fibrous dysplasia. A report of two cases," Radiology, vol. 106, no. 1, pp. 167-170, 1973.

[19] R. Takechi, T. Shinozaki, T. Fukuda, T. Yanagawa, and K. Takagishi, "Involvement of the proximal tibial epiphysis by monostotic fibrous dysplasia," Clinical Imaging, vol. 33, no. 2, pp. 154$157,2009$. 


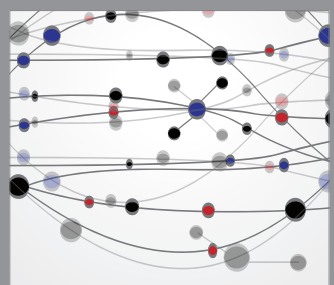

The Scientific World Journal
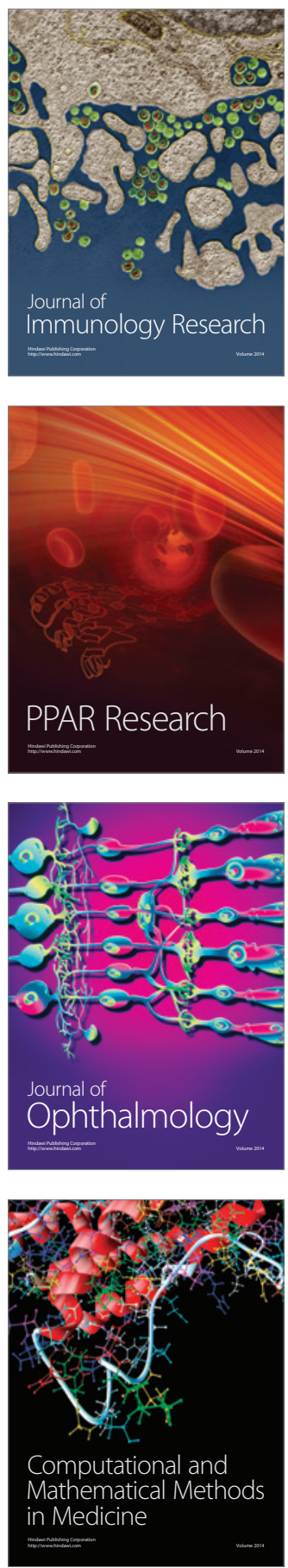

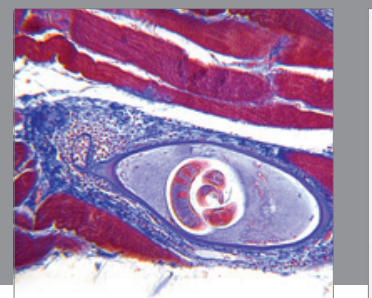

Gastroenterology

Research and Practice
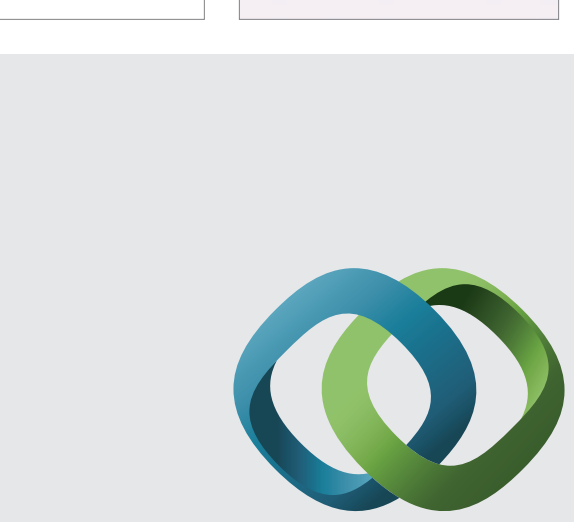

\section{Hindawi}

Submit your manuscripts at

http://www.hindawi.com
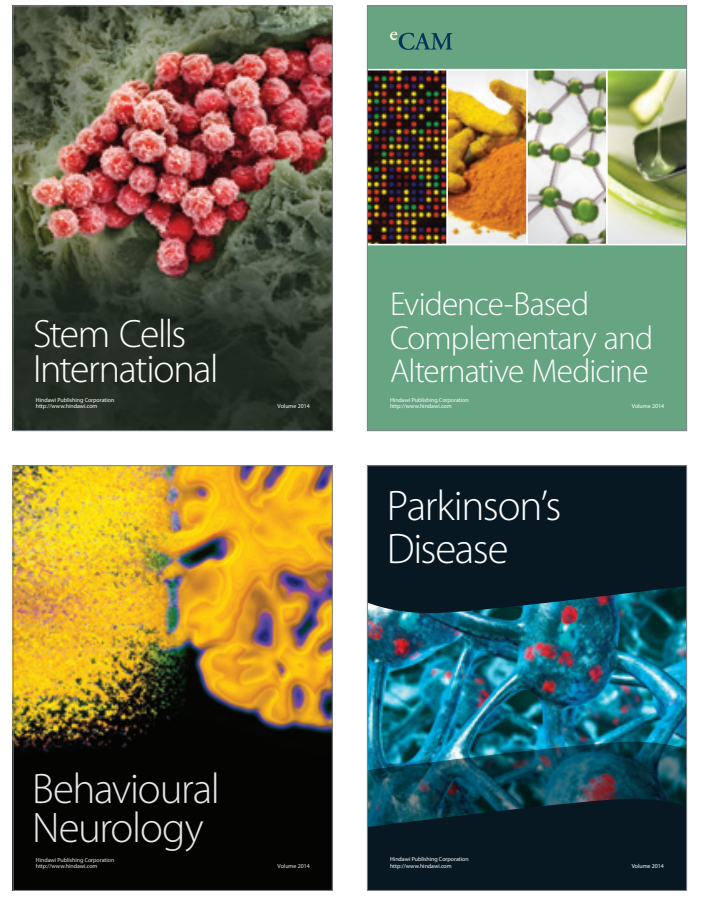
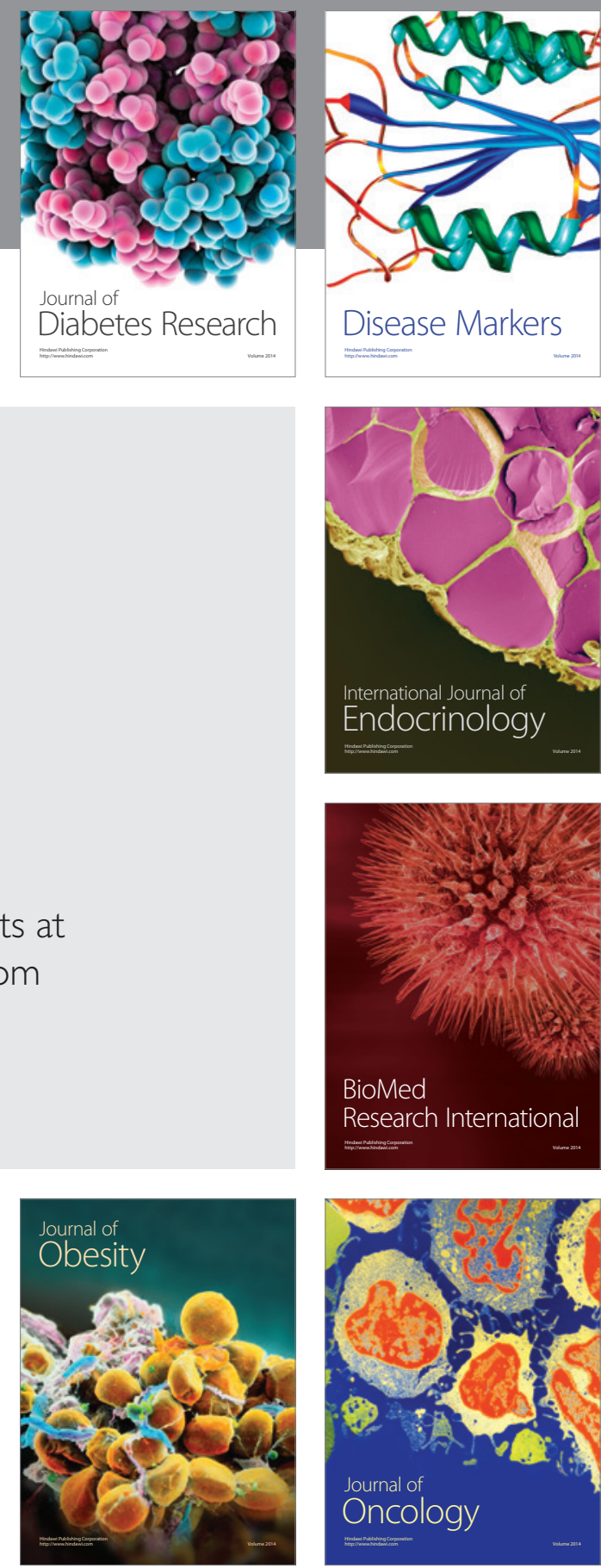

Disease Markers
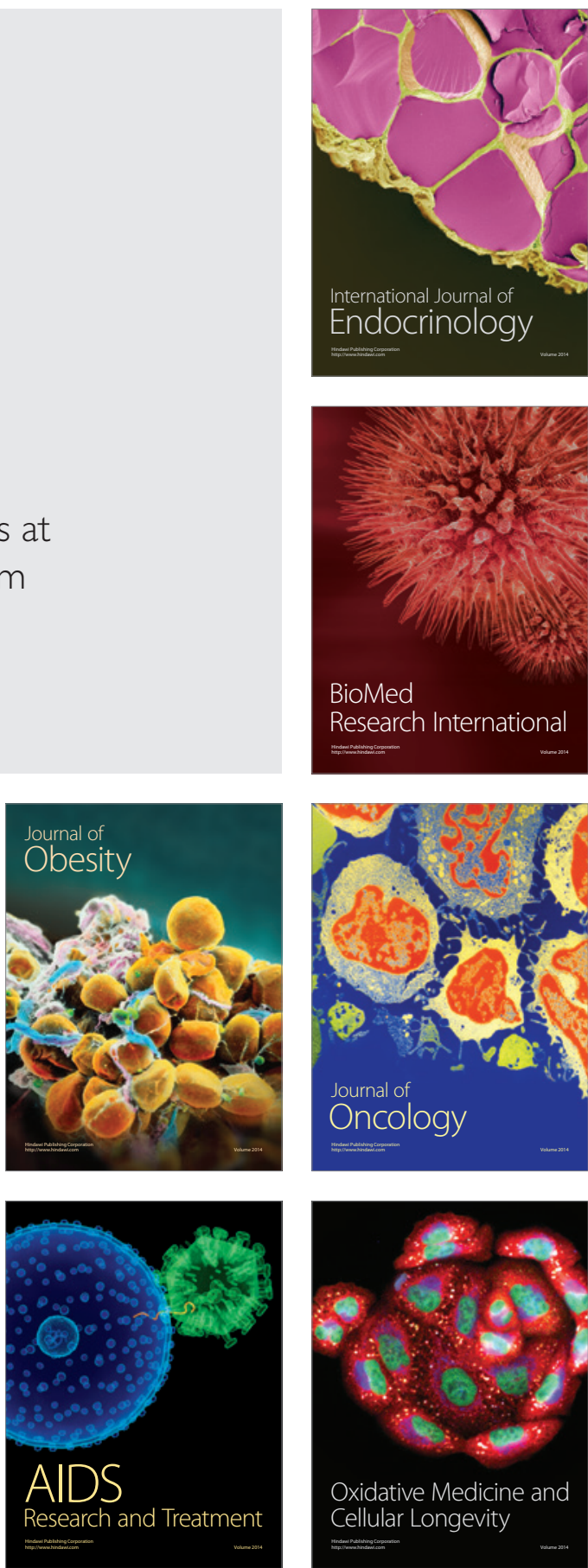